\title{
Analysis of Energy Balance for a Steel Electric Arc Furnace
}

\author{
BOGDAN DIACONU ${ }^{\mathrm{a}}$, LUCICA ANGHELESCU ${ }^{\mathrm{b}}$, MIHAI CRUCERU ${ }^{\mathrm{c}}$ \\ Energy and Environment Department \\ University "Constantin Brancusi" of Targu-Jiu \\ Calea Eroilor 30, Targu Jiu, 210152, Gorj \\ ROMANIA
}

\begin{abstract}
A process and energy analysis was performed for an Electric Arc Furnace for steel production in order to determine the energy efficiency defined as losses contribution in the total energy input. Process analysis was performed during operation for one batch, measuring the relevant process parameters. Energy balance revealed that a significant potential for improvement exists, the main directions being reducing the cooling water loss (for example, by implementing a heat recovery system), reducing the loss during loading and adjustment by implementing technology changes and automation and reducing the loss through exhaust gas. Although implementation of heat recovery systems on the cooling water circuit and exhaust gas duct will not influence the actual process energy efficiency, it is expected to improve the overall energy expenditure by integrating other heat consuming equipment.
\end{abstract}

Key-words:- Energy efficiency; Electric Arc Furnace; Steel Production; Specific Consumption

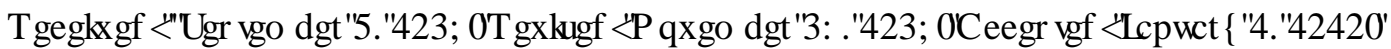

Published: January 29, 2020.

\section{Introduction}

Electric Arc Furnaces (EAF) have several advantages over gas-fired melting furnaces, the most important being the quality of the final product. In a recent study carried out at Berkeley's Department of Mechanical Engineering, University of California, Smith [1] compared melting in a gas-fired crucible furnace with an electric resistance crucible furnace. In order to ensure statistical significance several hundreds of test specimens were used. Tensile strength, yield strength and elongation properties were almost uniformly superior in the electrically melted samples regardless of the type of molds used. The mean mechanical properties of test bars melted in the gas-fired furnace reached only $80 \%$ of the mean values of electrically melted test bars. Another interesting and important result derived from the study was the dispersion of the mechanical properties from the mean value, which is significantly higher in the case of gas-fired furnaces. Optimization and transient regime studies of EAF are usually based on empirical models to describe the dynamics of the oxy-fuel burner during the melting stages of a batch [2]. These models do not perform well for optimization purposes as they fail to describe the effect that variations on both the scrap density and the flow rate of the fuel have on the heat exchanges between the oxy-fuel flames and the solid scrap. Henandez et al [2] developed a theoretical model based on analytical equations of the processes allowing estimating the energy contributions of the oxy-fuel burner for variable scrap densities and flow rates. For the case study considered, the authors found that the radiative heat transfer mechanisms account for almost $30 \%$ of the total emitted energy of the burner. On the other hand, convective mechanisms are variable during the batch time and present a linear behavior that drops in time from 35\% to $0 \%$ at the point where $75 \%$ of the total solid scrap it is molten.

It is a fact that steel industry contributes significantly to the $\mathrm{CO}_{2}$ emissions due to anthropogenic activities [3, 4]. Kuramochi [5] pointed out that higher costs for carbon emission certificates drive the steel industry towards the electric arc furnace route, due to lower total emissions compared to the integrated route. In this context, Keplinger et al [6] argue that a promising strategy for electric steel plant operators which has the potential to improve considerably the sustainability of the process is the installation of a heat recovery system (HRS). Steinparzer et al [7] performed a numerical and experimental study of an EAF with a molten salt HRS focusing on the energy balance, influence of hot corrosion and dust 
settlement. Given the batch operation of a typical $\mathrm{EAF}$, integration of a heat storage tank was considered. With the integration of the thermocline storage tank, it was found that it was possible to fully detach the fluctuating energy source from the constant steam production. Other attempts to improve the overall energy efficiency of EAFs with the help of heat recovery technologies include usage of phase change materials combined with superheated steam generation [8], application of nonlinear model predictive control methods [9], employment of advanced systems for cooling and heat recovery [10], etc.

\section{Description of the EAF Considered in the Analysis}

The schematic diagram of the EAF for which the energy balance will be carried out is presented in Figure 1. The main geometric elements of the EAF are presented in Table 1.

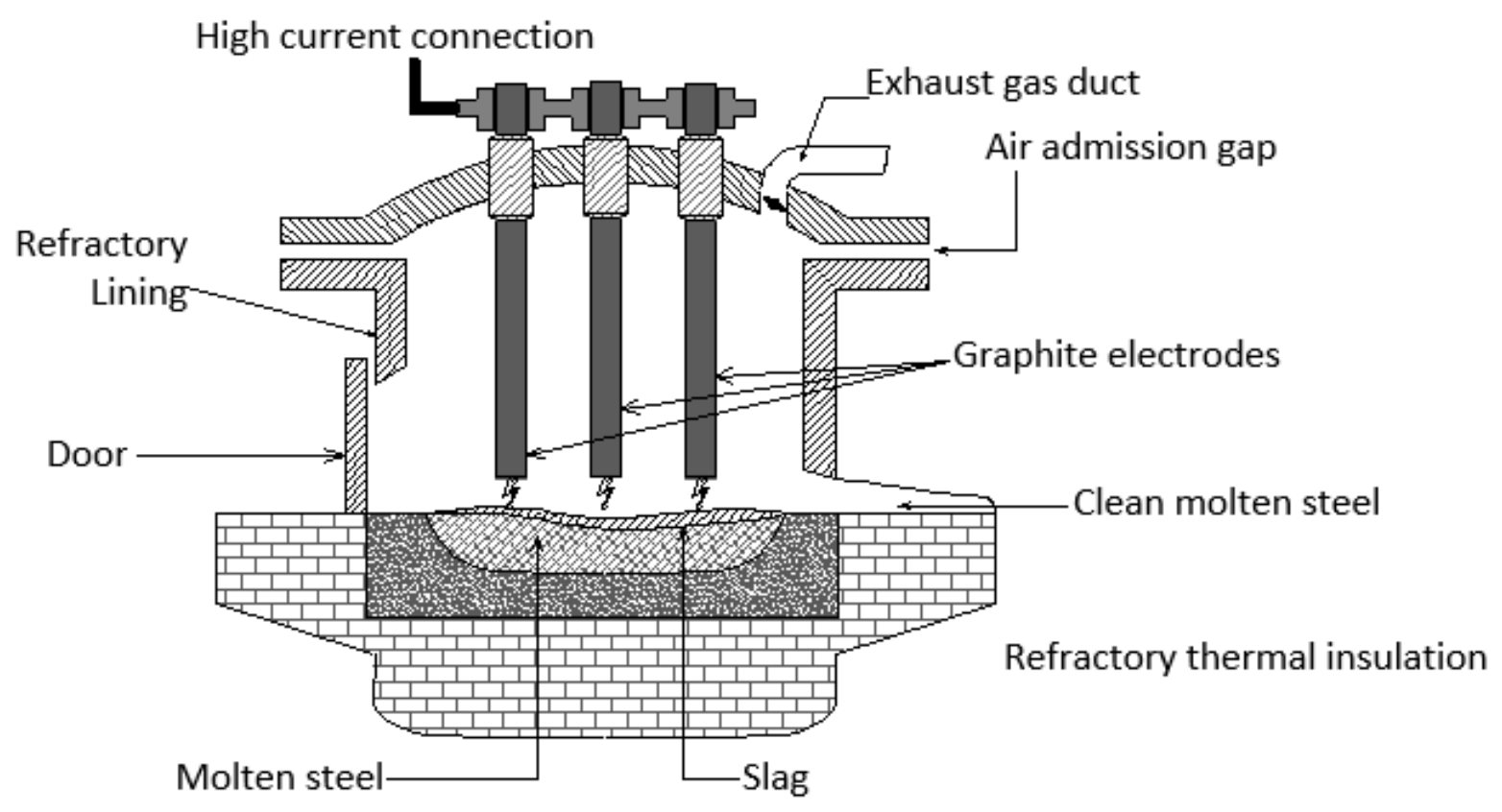

Fig.1. Axial cross section through the EAF

Table 1. Main geometric elements of the EAF

\begin{tabular}{|l|l|}
\hline Tank diameter & $3400 \mathrm{~mm}$ \\
\hline Molten metal collector diameter & $2400 \mathrm{~mm}$ \\
\hline Tank total surface area & $4.5 \mathrm{~m}^{2}$ \\
\hline Swivel roof surface area & $9.06 \mathrm{~m}^{2}$ \\
\hline Outer walls total surface area & $13.6 \mathrm{~m}^{2}$ \\
\hline Door surface area & $0.3 \mathrm{~m}^{2}$ \\
\hline Drain tapping spout surface area & $0.076 \mathrm{~m}^{2}$ \\
\hline Fireplace surface area & $7.15 \mathrm{~m}^{2}$ \\
\hline Fireplace lining material & $\begin{array}{l}\text { Refractory } \\
\text { bricks }\end{array}$ \\
\hline Electrodes material & Graphite \\
\hline
\end{tabular}

The power supply characteristics of the EAF are presented in Table 2

Table 2. Characteristics of the power supply

\begin{tabular}{|l|l|}
\hline Supply power transformer & $6000 / 127 \mathrm{~V}$ \\
\hline Rated current (secondary winding) & $5900 \mathrm{~A}$ \\
\hline Rated capacity & $2250 \mathrm{kVA}$ \\
\hline Power transformer efficiency & 0.92 \\
\hline Reactive load rated capacity & $350 \mathrm{kVA}$ \\
\hline Supply cable cross section & $3 \times 120 \mathrm{~mm}^{2}$ \\
\hline Supply cable length & $45 \mathrm{~m}$ \\
\hline
\end{tabular}




\section{Methods and Measurement Sheets}

\subsection{Identification of the Energy Flows}

The energy balance reference unit will be considered the batch (given the cyclic character of the process) and the energy will be expressed in kWh.

The input energy flows (metered either directly or by means of other parameters) are as follows:

- Electrical energy from the power grid, denoted $W_{\theta e}$ and metered directly by means of the individual energy meter

- Sensible heat of the load $W_{m}$

- Sensible heat of the cooling water entering the cooling system $W_{c w 1}$

- Sensible heat of the air $W_{L}$

- Exothermal chemical reaction released heat $W_{e x}$

- Heat resulting from electrodes burnout $W_{\text {eld }}$ The useful energy flows are identified as follows:

- The heat required to heat up (sensible), melt (latent) and superheat (sensible) the steel $W_{s t}$

- The sensible heat of the slag $W_{s l}$

- Endothermic chemical reactions absorbed heat $W_{e n}$

- The heat required to heat up, vaporize and superheat the water in the form of hygroscopic humidity and crystallization humidity in the feed materials $W_{\text {water }}$

The energy losses have the following components:

- Sensible heat of the gases leaving the furnace $W_{\text {gas }}$

- Radiative losses through the door and drain tapping spout $W_{\text {rad }}$

- Convective and radiative losses from electrodes and internal surfaces during the transient regime of adjustment and loading of the furnace (roof removed and electrodes are out of the active zone) $W_{\text {trans }}$

- Sensible heat of the cooling water leaving the cooling system $W_{c w 2}$

- Electrical losses of the power transformer, reactive load and supply cable $W_{\text {electric }}$

In order to carry out the energy balance, the following steps were taken:

\subsection{Material Balance - Inputs and Outputs}

The input material flows, consisting of prime materials required for the process are presented in
Table 3.A while outputs of the process are presented in Table 3.B.

Table 3. A. Material balance - inputs

\begin{tabular}{lll}
\hline Material & Symbol & $\begin{array}{l}\text { Value } \\
\mathrm{kg} / \text { batch }\end{array}$ \\
\hline Scrap iron & $\mathrm{G}_{1}$ & 6500 \\
Ferromanganese & $\mathrm{G}_{2}$ & 76 \\
Ferrosilicon & $\mathrm{G}_{3}$ & 44 \\
Ferrochrome & $\mathrm{G}_{4}$ & 97 \\
$\mathrm{Fe}_{2} \mathrm{O}_{3}$ & $\mathrm{G}_{5}$ & 146 \\
Calcium silicate & $\mathrm{G}_{6}$ & 6 \\
Silica manganese & $\mathrm{G}_{7}$ & 12 \\
Aluminum & $\mathrm{G}_{8}$ & 2 \\
Slaked lime & $\mathrm{G}_{9}$ & 410 \\
Calcium fluoride & $\mathrm{G}_{10}$ & 105 \\
Bauxite & $\mathrm{G}_{11}$ & 71 \\
Metallurgical coke & $\mathrm{G}_{12}$ & 73 \\
Petroleum coke & $\mathrm{G}_{13}$ & 36 \\
\hline Total load & $\mathrm{G}_{\mathrm{i}}$ & 7573 \\
Electrodes consumption & $\mathrm{G}_{\mathrm{c} \text {-eld }}$ & 55 \\
\hline Total input & $\mathbf{G}_{\mathbf{t}}$ & $\mathbf{7 6 3 3}$ \\
\hline
\end{tabular}

Table 3. B. Material balance - outputs

\begin{tabular}{lll}
\hline Material & Symbol & $\begin{array}{l}\text { Value } \\
\text { kg/batch }\end{array}$ \\
\hline Molten steel & $\mathrm{G}_{\text {st }}$ & 6710 \\
Molten slag & $\mathrm{G}_{\text {slag }}$ & 806 \\
Total product & $\mathrm{G}_{\mathrm{e}}$ & 7516 \\
Carbon reacted to $\mathrm{CO}_{2}$ & $\mathrm{G}_{\mathrm{C} / \mathrm{CO} 2}$ & 145.2 \\
Balance error & $\Delta G$ & -28.2 \\
\hline Total output & $\mathbf{G}_{\mathbf{l}}$ & $\mathbf{7 6 3 3}$ \\
\hline
\end{tabular}

\subsection{Measurements Sheet}

The following parameters were measured during the tests:

- Cooling water for door and electrodes (respectively) outlet temperature $t_{c w-\text { door }}=34^{\circ} \mathrm{C}, t_{c w-a l}=21^{\circ} \mathrm{C}$

- Batch processing time $\tau=4 h$

- Furnace openings surface area, door and exhaust duct (for radiative losses): $A_{\text {door }}=0.3 \mathrm{~m}^{2}$, $A_{e x}=0.076 m^{2}$

- Door and exhaust opening time (during one batch): $\tau_{\text {door }}=1 \mathrm{~h} / \mathrm{batch}, \tau_{e x}=0.4 \mathrm{~h} / \mathrm{batch}$

- Average furnace temperature during the door and exhaust opening time $T_{\text {door }}=1853 \mathrm{~K}$, $T_{e x}=1673 \mathrm{~K}$

- Average electrodes temperature during adjustment and loading: $T_{e l}=1593 \mathrm{~K}$ 
- Average swivel roof $t$ emperature during adjustment and loading $T_{e l}=1473 \mathrm{~K}$

- Average tank temperature during adjustment and loading $T_{\text {tank }}=1553 \mathrm{~K}$

- Electrodes radiative surface: $A_{\text {eld }}=4.24 \mathrm{~m}^{2}$

- Interior swivel roof radiative surface: $A_{i-\text { roof }}=5.7 \mathrm{~m}^{2}$

- Interior tank radiative surface: $A_{i-\text { tank }}=4.5 \mathrm{~m}^{2}$

- Per batch duration of radiative exchange from electrodes: $\tau_{\text {rad-el }}=0.5 \mathrm{~h} / \mathrm{batch}$

- Per batch duration of radiative exchange from swivel roof: $\tau_{\text {rad-r }}=0.167 \mathrm{~h} / \mathrm{batch}$

- Per batch duration of radiative exchange from tank: $\tau_{\text {rad-t }}=0.25 \mathrm{~h} / \mathrm{batch}$

- Exterior swivel roof surface area $A_{\text {e-roof }}=9.07 \mathrm{~m}^{2}$

- Exterior walls surface area $A_{\text {a-wall }}=13.6 \mathrm{~m}^{2}$

- Exterior fireplace surface area $A_{\text {e-fireplace }}=7.15 \mathrm{~m}^{2}$

- Average temperature of the exterior swivel roof surface: $T_{\text {roof }}=678 \mathrm{~K}$

- Average temperature of the exterior walls surface: $T_{\text {wall }}=460 \mathrm{~K}$

- Average temperature of the exterior fireplace surface: $T_{\text {fireplace }}=443 \mathrm{~K}$

- Duration of the losses from exterior surface is considered equal to the batch processing time

- Average environment temperature: $T_{e n v}=288 \mathrm{~K}$

- Per batch duration of power supply from the grid: $\tau_{\text {supply }}=3.5 \mathrm{~h} / \mathrm{batch}$, divided as follows:

- At $220 \mathrm{~V}$, with reactance load connected: $\tau_{\text {supply } 1}=0.25 \mathrm{~h} / \mathrm{batch}$

- At $220 \mathrm{~V}$, without reactance load: $\tau_{\text {supply } 2}=1.25 \mathrm{~h} / \mathrm{batch}$

- At $127 \mathrm{~V}$, without reactance load: $\tau_{\text {supply } 3}=2.0 \mathrm{~h} / \mathrm{batch}$

- Power transformer type: $6 \mathrm{kV} / 220$ (127) V, 50 $\mathrm{Hz}$, connection group Ynd11, cooling type ONAN

- Power transformer reactive losses at $220 \mathrm{~V}$ : $P_{r 1}=5.7 \mathrm{~kW}$

- Power transformer reactive losses at $127 \mathrm{~V}$ : $P_{r 2}=2.2 \mathrm{~kW}$

- Power transformer Joule losses (short-circuit regime) at nominal current $5900 \mathrm{~A}: P_{J 1}=29 \mathrm{~kW}$

- Power transformer Joule losses (short-circuit regime) at tap $220 \mathrm{~V}: P_{J 2}=23.2 \mathrm{~kW}$

- Average operating loads considered in the analysis:
- At $220 \mathrm{~V}$ tap with reactive load connected: $S_{1}=2250 \mathrm{kVA}$

- At $220 \mathrm{~V}$ tap without reactive load connected: $S_{2}=1550 \mathrm{kVA}$

- At $127 \mathrm{~V}$ tap without reactive load connected: $S_{3}=1100 \mathrm{kVA}$

- Power supply cable resistance (HV side): $R_{\text {cable }}=3.25 \times 10^{-2}$ Ohms

- Electrodes resistance, per phase (including connection to power transformer): $R_{e l}=4.2 \times 10^{-4}$ Ohms/phase

- Reactive load resistance, per phase: $R_{r l}=3.2 \times 10^{-2}$ Ohms/phase

- Per batch electrical energy from the grid: $W_{e \theta}=5903 \mathrm{kWh} / \mathrm{batch}$

- Prime materials initial temperature: $t_{m}=20^{\circ} \mathrm{C}$

- Molten steel temperature at the exit from furnace: $t_{\text {steal }}=1600^{\circ} \mathrm{C}$

- Slag temperature at the exit from furnace: $t_{\text {slag }}=1650^{\circ} \mathrm{C}$

- Water flow rate for cooling of the door: $D_{\text {cw-door }}=4.167 \times 10^{-3} \frac{\mathrm{m}^{\mathrm{s}}}{\mathrm{s}}=4.167 \mathrm{~kg} / \mathrm{s}$

- Water flow rate for cooling of the electrodes: $D_{\text {cw- } \mathrm{ll}}=4.027 \times 10^{-3} \frac{\mathrm{m}^{\mathrm{s}}}{\mathrm{s}}=4.027 \mathrm{~kg} / \mathrm{s}$

- Cooling water inlet temperature: $t_{\text {cr } 1}=15^{\circ} \mathrm{C}$

\section{Calculation of Energy Flows - Energy Balance Components}

i) Sensible heat of prime materials:

$W_{\text {mat }}=\sum_{i=1}^{13} G_{i} c_{i} t_{\text {mi }}$

Temperature of each prime material (from Table 2) will be considered the same, $20^{\circ} \mathrm{C}$. Using SI units, the equation above is rewritten to produce $\mathrm{kWh}$ :

$$
W_{\text {mat }}=\frac{\sum_{i=1}^{1 \mathrm{~s}} G_{\mathrm{i}} \mathrm{c}_{\mathrm{i}} \mathrm{t}_{\mathrm{mi}}}{3.6 \times 10^{6}}=23.2 \mathrm{kWh} / \mathrm{batch}
$$

ii) Heat released during exothermic chemical reactions has the following sources:

- Manganese, phosphorus, silica, chromium and carbon oxidation

- Slag formation reactions

The amount of manganese, phosphorus, silica, chromium and carbon that reacted is determined as the difference between the prime materials content and final product content. The latest are determined based on percentage values, determined by X-ray diffraction and presented in Table 4. 
Table 4. Manganese, phosphorus, silica, chromium and carbon content

\begin{tabular}{|l|l|l|l|l|l|}
\hline Element & $\mathrm{C}[\%]$ & $\begin{array}{l}\mathrm{Mn} \\
{[\%]}\end{array}$ & Si [\%] & P [\%] & $\begin{array}{l}\mathrm{Cr} \\
{[\%]}\end{array}$ \\
\hline Content & 0.475 & 0.85 & 0.237 & 0.025 & 1.0 \\
\hline
\end{tabular}

The total amount of heat released through exothermic reactions is determined after a series of calculations, based on the absolute amounts of prima materials given in Tables $2 \mathrm{a}$ nd $3 \mathrm{a}$ nd stoichiometric considerations: $W_{\text {mat }}=980 \mathrm{kWh} / \mathrm{batch}$

iii) Heat released through electrodes oxidation: $W_{e l}=G_{c-e l d} \cdot Q_{C}=\frac{55-34012 \times 10^{\mathrm{g}}}{3.6 \times 10^{6}}=519.5 \mathrm{kWh}(3)$ iv) Sensible heat of cooling water entering the cooling system

$$
\begin{array}{r}
W_{c w 1}=\frac{\left(Q_{c-\text { door }}+Q_{c-e l}\right) c_{p \text { water }} t_{c w 1} \tau}{3.6 \times 10^{6}}= \\
=2056 \mathrm{kWh} / \text { batch }
\end{array}
$$

v) Sensible heat of air entering the furnace: $W_{\text {air }}=V_{\text {air }} h_{\text {air }} /\left(3.6 \times 10^{6}\right)$

The air volume $V_{\text {air }}$ is given by: $V_{\text {air }}=V_{O_{2}}+V_{N_{2}}$. The volumes of oxygen and nitrogen are determined based on the chemical reactions occurring during the batch processing. For simplicity the intermediate results are omitted, resulting $V_{\text {air }}=1221.4 \mathrm{~m}_{\mathrm{N}}^{3} /$ batch

Considering the air enthalpy $h_{\text {air }}$ at the environment temperature: $W_{\text {air }}=6.6 \mathrm{kWh} / \mathrm{batch}$

vi) Energy consumption due to endothermic reactions. Details of the calculations based on stoichiometry principles are not included here for brevity. The amounts of $\mathrm{Fe}_{2} \mathrm{O}_{3}$ reacting (80\% reacts as $\mathrm{Fe}$ and the rest of $20 \%$ reacts as $\mathrm{FeO}$ ) [2].

The endothermic reactions heat is obtained as:

$$
\begin{aligned}
& W_{\text {end }}=Q \frac{F_{e_{2}} O_{g}}{F e} \cdot \frac{G E_{2} O_{g}}{F e}+ \\
& +Q_{\mathrm{Fe}_{2} \mathrm{O}_{3} / \mathrm{FeO}_{\mathrm{B}}} \cdot G_{\mathrm{Fe}_{\mathrm{E}} \mathrm{O}_{\mathrm{g}} / \mathrm{Fe}_{\mathrm{B}} \mathrm{O}}=248 \mathrm{kWh} / \mathrm{batch}(
\end{aligned}
$$

vii) The amount of heat required to melt and superheat the steel:

$$
W_{\text {steel }}=\frac{G_{\text {steel }}\left[c_{p \text { solid steel }} t_{\text {melt steel }}+r_{\text {steel }}+c_{\text {pmolten steel }}\left(t_{\text {steel }}-t_{\text {melt steel }}\right)\right]}{3.6 \times 10^{6}}=2688 \mathrm{kWh} / \mathrm{batch}
$$

viii) The amount of heat required to melt and superheat the slag:

$$
\begin{aligned}
& W_{\text {slag }}=\frac{G_{\text {slag }}\left(c_{p \text { slagt }} \text { slag }+q_{\text {slag }}\right)}{3.6 \times 10^{6}} \\
& W_{\text {slag }}=495 \mathrm{kWh} / \mathrm{batch}
\end{aligned}
$$

In order to calculate the amount of slag $G_{\text {slag }}$ the following slag components must be considered:

- $\mathrm{SiO}_{2}, \mathrm{P}_{2} \mathrm{O}_{5}, \mathrm{MnO}, \mathrm{Cr}_{2} \mathrm{O}_{3}$ resulting from the exothermic reactions

- $\mathrm{FeO}$ resulting from $\mathrm{Fe}_{2} \mathrm{O}_{3}$ endothermic reactions

$$
W_{\text {water }}=\frac{\left(A_{1}+A_{2}\right)\left[c_{p \text { water }}\left(100-t_{m}\right)+r_{\text {water }}+c_{p \text { water vapour }}\left(t_{\text {exhaust }}-100\right)\right]+r_{c-F e_{2}} o_{g} A_{2}}{3.6 \times 10^{6}}
$$

Where:

- $r_{\text {water }}$ is the water latent heat of vaporization, $2260 \mathrm{~kJ} / \mathrm{kg}$

- $r_{\mathrm{c}-\mathrm{Fe}_{2} \mathrm{O}_{\mathrm{s}}}=330 \frac{\mathrm{kJ}}{\mathrm{kg}}$ is the $\mathrm{Fe}_{2} \mathrm{O}_{3}$ crystallization heat.

With this values, $W_{\text {water }}=30.8 \mathrm{kWh} / \mathrm{batch}$
- Lime, calcium fluoride, calcium silicate, silica manganese, aluminum and bauxite as prima materials (as presented in Table3.A)

$q_{\text {slag }}$ is the slag latent heat of melting, $q_{\text {slag }}=209 \mathrm{~kJ} / \mathrm{kg}$

ix) Heat required for heating up and vaporizing the humidity of the prime materials $\left(A_{1}=10 \mathrm{~kg}\right)$ and $\mathrm{Fe}_{2} \mathrm{O}_{3}$ crystallization humidity $\left(A_{2}=14.6 \mathrm{~kg}\right)$ is determined considering that the resulting water vapor will heat to $800{ }^{\circ} \mathrm{C}$ (exhaust gas evacuation temperature): x) Heat loss through exhaust gas leaving the furnace

The exhaust gas mixture leaving the furnace consists of carbon dioxide and nitrogen. The total heat loss corresponding to the exhaust gas is determined based on the gas volume and exhaust temperature: 


$$
W_{\text {gas }}=\frac{V_{\mathrm{CO}_{2}}-h \mathrm{CO}_{2}+V_{\mathrm{N}_{2}}-h_{\mathrm{N}_{2}}}{3.6 \times 10^{6}}
$$$$
W_{\text {gas }}=422,8 \mathrm{kWh} / \mathrm{batch}
$$

The gas volumes are determined based on stoichiometry considerations and the enthalpies are determined at the exhaust temperature, $800{ }^{\circ} \mathrm{C}$.

xi) The heat loss through orifices and openings. The main openings that cause heat losses are the loading door $W_{\text {raddoor }}$ and the exhaust duct $W_{\text {radex }}$ :

$$
W_{\text {rad }}=W_{\text {rad door }}+W_{\text {radex }}
$$

Radiative loss equation for the door opening is given by:

$W_{\text {rad door }}=\sigma \varphi A_{\text {door }} \tau_{\text {door }}\left[T_{\text {door }}^{4}-T_{\text {env }}^{4}\right] \cdot \frac{1}{3.6 \times 10^{6}}$

Where,

$A_{\text {door }}=0.3 \mathrm{~m}^{2}$ is the door surface area,

$\varphi=0.64$ is view factor for the door opening (given by the furnace manufacturer),

$\tau_{\text {door }}=1 \mathrm{~h}=3600 \mathrm{~s}$ is the door opening time (given in Section 3.3).

$W_{\text {rad door }}=130 \mathrm{kWh} / \mathrm{batch}$

Radiative loss equation for the exhaust opening is given by:

$$
W_{\text {radex }}=\sigma \varphi A_{e x} \tau_{\operatorname{ex}}\left[T_{\operatorname{ex}}^{4}-T_{e m v}^{4}\right] \cdot \frac{1}{3.6 \times 10^{6}}
$$

$A_{\text {ex }}=0.076 \mathrm{~m}^{2}$ is the door surface area,

$\varphi=0.58$ is the view factor for the exhaust opening (given by the furnace manufacturer),

$\tau_{e x}=0.4 h=1440 \mathrm{~s}$ is the exhaust opening time (given in Section 3.3).

In the radiative exchange equations above $\sigma=5.67 \times 10^{-8} \frac{W}{m^{2} K^{4}}$ is Boltzmann constant. Plugging the numeric values into the radiative exchange equations the following values are obtained:

$$
W_{\text {rad door }}=131 \mathrm{kWh} / \mathrm{batch}
$$$$
W_{\text {radex }}=7 \mathrm{kWh} / \text { batch }
$$

xii) Convective and radiative loss during the adjustment and loading period

During this stage of the furnace operation the swivel roof is lifted and heat is lost from electrodes and interior surfaces of the swivel roof and tank. The generalized Newton law for convection can be employed to determine this type of losses (from a hot surface to the environment):

$$
q=\alpha_{e}\left(t_{\text {surface }}-t_{\text {env }}\right)\left[\frac{W}{m^{2}}\right]
$$

$\alpha_{e}$ is the equivalent heat transfer through convection and radiation and is given by the following semiempirical equation:

$$
\begin{aligned}
\alpha_{e}= & m\left(t_{\text {surface }}-t_{\text {env }}\right)^{\text {u.2s }}+ \\
& +\frac{c}{t_{\text {surface }}-t_{\text {env }}} \cdot\left[T_{\text {surface }}^{4}-T_{\text {env }}^{4}\right] \cdot \frac{1}{3.6 \times 10^{6}}
\end{aligned}
$$

Where:

- $m=2.2$ is a coefficient depending on the surface shape and orientation, $C$ is the radiative exchange coefficient, depending on the surface material and surface condition:

- For electrodes: $\quad C=4.64 \times 10^{5} \frac{W}{m^{2} K^{4}}$

- For interior surfaces: $C=4.76 \times 10^{5} \frac{m^{2} K^{4}}{m^{2} K^{4}}$

Given the temperatures, geometric data and duration of the opening, all of these presented in Section 3.3, the following values are calculated:

- Electrodes: $W_{c+r_{i} e l}=678 \mathrm{kWh} / \mathrm{batch}$

- Swivel roof: $W_{c+r_{2} \text { roof }}=229 \mathrm{kWh} /$ batch

- Tank: $W_{c+r_{i} t}=330 \mathrm{kWh} /$ batch

The total amount of heat lost through convection and radiation during adjustment and loading is the sum of the three components presented above:

\section{$W_{c+r}=1237 \mathrm{kWh} /$ batch}

xiii) Convective and radiative loss from the exterior surfaces of the swivel roof, walls and fireplace is determined in the same way as above, with the values of the radiative exchange coefficients and shape/orientation coefficient $m$ given in Table 5 .

Table 5. Radiative exchange and shape/orientation coefficients for walls, roof and fireplace

\begin{tabular}{llll}
\hline Coefficients & Walls & Roof & Fireplace \\
\hline$C\left[W^{-2} K^{-4}\right]$ & $4.41 \times 10^{5}$ & $4.41 \times 10^{5}$ & $4.41 \times 10^{5}$ \\
$\left(^{1}\right)$ & & \\
$m\left({ }^{2}\right)$ & 2.2 & 2.8 & 1.8 \\
\hline$\left(^{1}\right)-$ Same type of surface for all components, brick \\
covered with conventional plaster \\
$\left(^{2}\right)-$ Depends on the orientation of the surface
\end{tabular}

Considering the geometric elements, temperatures and duration of the losses equal to the batch duration, the following components of the convective and radiative loss from the exterior surfaces of the swivel roof, walls and fireplace are calculated:

Swivel roof: $W_{e x t_{i} c+r_{r} \text { roof }}=530 \mathrm{kWh} / \mathrm{batch}$

Walls: $W_{\text {ext }}$ ctrwalls $=178 \mathrm{kWh} / \mathrm{batch}$

Fireplace: $W_{e x t_{i} c+r f f}=73 \mathrm{kWh} /$ batch

The total amount of heat lost through convection and radiative from the exterior surfaces of the swivel roof, walls and fireplace: 
$W_{\text {ext } t_{i}+r}=781 \mathrm{kWh} / \mathrm{batch}$

xiv) Sensible heat of cooling water leaving the cooling system (parameters values given in Section 3.3):

$$
\begin{gathered}
W_{c w 2}=\left(\frac{D_{c w-d o o r} c_{p w a t e r} t_{c w-d o o r}}{3.6 \times 10^{6}}+\right. \\
\left.+\frac{D_{\text {cw-Elcpwatert }} t_{c w-E l}}{3.6 \times 10^{6}}\right) \cdot \tau \\
W_{c w 2}=\left(\frac{4.167-4.185-34}{3.6 \times 10^{6}}+\frac{4.027-4.185-21}{3.6 \times 10^{6}}\right) \cdot 4 \\
W_{c w 2}=3440 \mathrm{kWh} / \text { batch }
\end{gathered}
$$

xv) Electrical losses consist of the following components:

$$
\begin{aligned}
& \text { Transformer losses (power): } \\
& \Delta P_{\text {trafo }}=\Delta P_{0} \tau_{c}+\beta^{2} \Delta P_{s c} \tau_{\text {load }}
\end{aligned}
$$

$\Delta P_{0}, \Delta P_{s c}-$ no load, short circuit (respectively) losses of the transformer

$\tau_{c}$ - duration of connection to the grid

$\tau_{\text {load }}-$ duration of operation under load

$\beta$ - mean value of the load coefficient over the interval $\tau_{\text {load }}$

The nominal power of the transformer is determined as follows:

on the $127 \mathrm{~V}$ tap (LV winding):

$$
\begin{gathered}
S_{n}=\sqrt{3} U_{n} I_{n}=\sqrt{3} \cdot 127[\mathrm{~V}] \cdot 5900[\mathrm{~A}] \\
S_{n}=1298 \mathrm{kVA}
\end{gathered}
$$

on the $220 \mathrm{~V}$ tap (LV winding):

$$
S_{n}=\sqrt{3} U_{n} I_{n}=\sqrt{3} \cdot 220[\mathrm{~V}] \cdot 5900[\mathrm{~A}]==2250 \mathrm{kVA}
$$

For the three values of the load, the transformer losses are given in Section 3.3. The mean values of the load coefficients $\beta$ corresponding to the three operating regimes can be determined:

$$
\begin{aligned}
& \beta_{1}=\frac{s_{1}}{s_{n}}=\frac{2250}{2250}=1, \quad \beta_{2}=\frac{s_{2}}{s_{n}}=\frac{1550}{2250}=0.69, \\
& \beta_{3}=\frac{s_{g}}{s_{n}}=\frac{1100}{1300}=0.85
\end{aligned}
$$

The power transformer losses (energy per batch) can now be calculated as the sum of losses corresponding to each operation regime, with the relevant parameters from Section 3.3:

$$
\begin{aligned}
& \Delta W_{\text {trafo }}=\left(P_{01}+\beta_{1}^{2} P_{s c-1}\right) \tau_{1}+\left(P_{02}+\right. \\
& \left.+\beta_{2}^{2} P_{s c-2}\right) \tau_{2}+\left(P_{03}+\beta_{3}^{2} P_{s c-3}\right) \tau_{3} \\
& \Delta W_{\text {trafo }}=75.5 \mathrm{kWh} / \text { batch }
\end{aligned}
$$

- Joule losses in the transformer power supply cable:
Joule losses value depends on the current value in the three operating regimes. The current values in the $\mathrm{HV}$ and $\mathrm{LV}$ windings corresponding to the three regimes are as follows:

$$
\begin{aligned}
& I_{H V 1}=S_{1} /\left(\sqrt{3} U_{H V}\right)=2250 /(\sqrt{3} \cdot 6)=216 \mathrm{~A} \\
& I_{H V 2}=S_{2} /\left(\sqrt{3} U_{H V}\right)=1550 /(\sqrt{3} \cdot 6)=149 \mathrm{~A} \\
& I_{H V 3}=S_{3} /\left(\sqrt{3} U_{H V}\right)=1100 /(\sqrt{3} \cdot 6)=106 \mathrm{~A} \\
& \text { LV side: } \\
& I_{L V 1}=S_{1} /\left(\sqrt{3} U_{L V 1}\right) \\
& I_{L V 1}=2250 /(\sqrt{3} \cdot 0.220)=5900 \mathrm{~A} \\
& I_{L V 2}=S_{2} /\left(\sqrt{3} U_{L V 2}\right) \\
& I_{L V 2}=1550 /(\sqrt{3} \cdot 0.220)=4065 \mathrm{~A} \\
& I_{L V 3}=S_{3} /\left(\sqrt{3} U_{L V 1}\right) \\
& I_{L V 3}=1100 /(\sqrt{3} \cdot 0.220)=5000 \mathrm{~A}
\end{aligned}
$$

In the three equations above the indexes 1-3 correspond to the three operation regimes described in Section 3.3.

- The Joule losses in the power transformer supply cable can be determined from the expression:

$$
\Delta W_{\text {cable }}=3 R_{\text {cable }} \sum_{i=1}^{3} I_{H V_{i} i}^{2} \tau_{i} \times 10^{-3}
$$

$\Delta W_{\text {cable }}=3 \cdot 0.0325 \cdot\left(216^{2} \cdot 0.25+149^{2} \cdot 1.25+\right.$ $\left.+106^{2} \cdot 2\right) \cdot 10^{-3}$

$\Delta W_{\text {cable }}=6.1 \mathrm{kWh} / \mathrm{batch}$

- The Joule losses in the reactive load:

$$
\Delta W_{r l}=3 R_{\text {react }} I_{H V 1} \tau_{1} \cdot 10^{-3}
$$

$\Delta W_{r l}=3 \cdot 0.032 \cdot 216^{2} \cdot 0.25 \cdot 10^{-3}$

$\Delta W_{r l}=1.1 \mathrm{kWh} / \mathrm{batch}$

- The Joule losses in the electrodes:

$$
\Delta W_{\text {electrodes }}=3 R_{e l} \sum_{i=1}^{3} I_{L V i}^{2} \tau_{i} \times 10^{-3}
$$

$\Delta W_{\text {electrodes }}=3 \cdot 0.42 \cdot\left(5900^{2} \cdot 0.25+\right.$

$\left.+4065^{2} \cdot 1.25+5000^{2} \cdot 2\right) \cdot 10^{-3}$

$\Delta W_{\text {electrodes }}=101 \mathrm{kWh} / \mathrm{batch}$

The total value of electrical losses:

$$
\begin{array}{r}
\Delta W_{\text {el }}=\Delta W_{\text {trafo }}+\Delta W_{\text {cable }}+\Delta W_{r l}+ \\
+\Delta W_{\text {electrodes }}
\end{array}
$$

$\Delta W_{e l}=183 \mathrm{kWh} /$ batch

\section{Results and Discussion}

\subsection{Total Inputs, Outputs and Closure Error}


The absolute closure error, given by the difference between gross outputs (with losses included) and inputs:

$$
\begin{gathered}
\varepsilon=\text { INPUTS }- \text { (OUTPUTS + LOSSES) } \\
\varepsilon=-223.2 \mathrm{kWh} / \text { batch }
\end{gathered}
$$

which is equivalent to the relative error:

$$
\delta=\frac{\|s\|}{\text { INPUTS }} \times 100=2.3 \%
$$

The closure error value falls within accepted limits, which means the balance is valid and the results are meaningful. This value can be further used in the quantitative and qualitative interpretation of the energy balance and formulation of recommendations.

\subsection{Energy Balance Analysis}

In order to compare the energy balance for the furnace considered with other results the energy balance will be reformulated as follows:

- The energy balance will be expressed in $\mathrm{kWh} /$ ton of steel considering the net mass of steel (Table 3.B)

- The heat removed by the cooling water (the difference between heat carried by entering cooling water $W_{c w 1}$ and heat carried by cooling water leaving the cooling system $W_{c w_{2}}$ ) will be considered as an output only, as $W_{\text {cw2 } 2}-W_{\text {cw1 } 1}$ )

The gross efficiency of the furnace in terms of energy can be determined:

$$
\eta=1-\frac{\text { LOSSES }}{\text { INPUT }}=0.44
$$

This value may appear very low, however it must not be interpreted in terms of a conventional energy conversion process efficiency. The value must be related to the specific energy consumption, which is $880 \mathrm{kWh} /$ ton of steel). In terms of specific energy consumption per ton of steel produced the EAF performs within the limits specified for this type of equipment [13].

The losses relative contribution has to be investigated in order to identify possible measures for increasing the energy efficiency of the process. The highest value of the losses corresponds to the cooling water, $33.41 \%$. Integrating the heat recovery from the cooling water in the process can increase considerably the overall efficiency of the process (but not the actual efficiency of the furnace itself). However, the low thermal potential of the cooling water limits significantly its applicability. Re-design of the cooling system in such way that the cooling water leaves with a higher temperature can be a solution. However, a CFD study of the temperature field must be carried out in order to ensure the proper conditions of the process and technology requirements.

Another important component is the loss through exterior surfaces $(18.83 \%)$. Although this value is relatively small, there is a high potential to recover the sensible heat of the exhaust gas due to their very high thermal potential (approximately $800^{\circ} \mathrm{C}$ ) [8]. Constructive modifications are required for the EAF if this option is considered. Another advantage of implementation a HRS on the exhaust gas system is that cooling the gas allows implementation of a highly efficient gas cleaning system, increasing the sustainability of the steel production process.

Heat loss during adjustment and loading is the next component with a significant contribution in the total $(29.84 \%)$. The high value of these losses is explained by the intense radiative exchange from the hot interior surfaces to the environment. The key factor influencing this type of losses is the loading time. The other factors are the temperatures of the interior surfaces and electrodes, which are conditioned by the process nature and cannot be modified.

\section{Conclusions}

Process analysis and energy balance was performed for an EAC furnace with the purpose of. The objective of the study was to identify qualitatively and quantitatively the material and energy flows, especially the losses. A preliminary material balance was carried out in order to ensure the correctness of working hypothesis and conditions. Given the complex nature of the steel production in EAC furnaces consisting of both electrical and thermal energy conversion processes the energy balance had to account for both types of energy flows. It was found that the energy efficiency of the process - determined in terms of losses weight in the total energy input - is relatively low, approximately $44 \%$. This value is however in the range of conventional EAFs [11].

The contribution of losses components in the total was identified. It is important to notice that a significant increase of the energy efficiency can only be achieved by intervening on those losses components with a significant weight in the total:

- heat loss with cooling water

- heat loss during adjustment and loading 
- heat loss through exterior surfaces

- heat loss with exhaust gas

No significant positive effect can be achieved by reducing electrical losses and heat loss through orifices and openings because these losses have already a small contribution in the total.

Any measure to improve the energy efficiency of the process bears an economic cost [12] in addition to the modifications of the process, which have to be investigated in order to maintain optimal conditions of the process. Higher energy efficiency rates can be obtained if a combined approach process based and economic [13] is considered.

\section{References:}

[1] Frank B. Smith, Gas-fired vs. electric resistance melting of aluminum alloys, University of California at Berkeley's Department of Mechanical Engineering, Melting Comparison Studies

[2] J.D. Hernandez, L. Onofi, S. Engell, Model of an Electric Arc Furnace Oxy-Fuel Burner for dynamic simulations and optimization purposes, IFAC Papers On Line 52-14 (2019) 30-35

[3] Donald Huisingh, Zhihua Zhang, John C. Moore, Qi Qiao, Qi L, Recent advances in carbon emissions reduction: policies, technologies, monitoring, assessment and modeling, Journal of Cleaner Production 103 (2015) 1-12

[4] International Energy Agency, Energy and Air Pollution - World Energy Outlook 2016: Special Report.

[5] Takeshi Kuramochi, Assessment of midterm $\mathrm{CO}_{2}$ emissions reduction potential in the iron and steel industry: a case of Japan, Journal of Cleaner Production 132 (2016) 81-97

[6] Thomas Keplinger, Markus Haider, Thomas Steinparzer, Andreas Patrejko, Paul Trunner, Manfred Haselgrübler, Dynamic simulation of an electric arc furnace waste heat recovery system for steam production, Applied Thermal Engineering 135 (2018) 188-196

[7] Thomas Steinparzer, Markus Haider, Florian Zauner, Gerhard Enickl, Marcel Michele-Naussed, Andreas Christian Horn, Electric Arc Furnace OfGas Heat Recovery and Experience with a Testing Plant, Steel Research International, 13 August 2013

[8] Fabio Dal Magro, Stefano Savino, Antonella Meneghetti, Gioacchino Nardin, Coupling waste heat extraction by phase change materials with superheated steam generation in the steel industry, Energy 137 (2017) 1107-1118

[9] Smriti Shyamal, Christopher L.E. Swartz, Realtime energy management for electric arc furnace operation, Journal of Process Control 74 (2019) $50-62$

[10] Josue Contreras-Serna, Carlos I. RiveraSolorio, Marco A. Herrera-Garcia, Study of heat transfer in a tubular-panel cooling system in the wall of an electric arc furnace, Applied Thermal Engineering 148 (2019) 43-56

[11] Marcus Kirschen,Victor Risonarta, Herbert Pfeifer, Energy efficiency and the influence of gas burners to the energy related carbon dioxide emissions of electric arc furnaces in steel industry, Energy 34 (2009)

[12] Chong Chen, Ying Liu, Maneesh Kumar, Jian Qin, Energy consumption modeling using Deep Learning Technique - A case study of EAF, $51^{\text {st }}$ Conference on $\mathrm{M}$ anufacturing Systems, Procedia CIRP 72 (2018) 1063-1068

[13] Mudassir M. Rashid, Prashant Mhaskar, Christopher L.E. Swartz, Multi-rate modeling and economic model predictive control of the electric arc furnace, Journal of Process Control 40 (2016) 50-61 